\title{
Upregulation of E2F8 promotes cell proliferation and tumorigenicity in breast cancer by modulating G1/S phase transition
}

\author{
Liping Ye ${ }^{1, *}$, Ling Guo ${ }^{2, *}$, Zhenyu $\mathrm{He}^{3, *}$, Xi Wang ${ }^{4}$, Chuyong Lin ${ }^{1}$, Xin Zhang ${ }^{1}$, \\ Shu Wu ${ }^{1}$, Yong Bao ${ }^{3}$, Qi Yang ${ }^{2}$, Libing Song ${ }^{1}$, Huanxin Lin ${ }^{3}$ \\ ${ }^{1}$ Department of Experimental Research, State Key Laboratory of Oncology in Southern China, Collaborative Innovation \\ Center for Cancer Medicine, Sun Yat-sen University Cancer Center, Guangzhou 510060, People's Republic of China \\ ${ }^{2}$ Department of Nasopharyngeal Carcinoma, State Key Laboratory of Oncology in Southern China, Collaborative Innovation \\ Center for Cancer Medicine, Sun Yat-sen University Cancer Center, Guangzhou 510060, People's Republic of China \\ ${ }^{3}$ Department of Radiation Oncology, State Key Laboratory of Oncology in Southern China, Collaborative Innovation Center \\ for Cancer Medicine, Sun Yat-sen University Cancer Center, Guangzhou 510060, People's Republic of China \\ ${ }^{4}$ Department of Breast Surgery, State Key Laboratory of Oncology in Southern China, Collaborative Innovation Center for \\ Cancer Medicine, Sun Yat-sen University Cancer Center, Guangzhou 510060, People's Republic of China \\ *These authors have contributed equally to this work \\ Correspondence to: Huanxin Lin, e-mail: linhx@sysucc.org.cn
}

Keywords: E2F8, proliferation, tumorigenicity, breast cancer, cell cycle

Received: November 02, $2015 \quad$ Accepted: February 25, 2016

Published: March 16, 2016

\section{ABSTRACT}

E2F transcription factors are involved in cell cycle regulation and synthesis of DNA in mammalian cells, and simultaneously play important roles in the development and progression of cancer when dysregulated. E2F8, a novel identified E2F family member, was found to be associated with the progression of several human cancers; however, the biological role and clinical significance of E2F8 in breast cancer remain to be further elucidated. Herein, we report that E2F8 is robustly elevated in breast cancer cell lines and clinical breast cancer tissue samples, respectively. The high expression level of E2F8 significantly correlates with clinical progression $(P=0.001)$, poor patient survival $(P<0.001)$ and a high Ki67 staining index $(P=0.008)$ in 187 human breast cancer specimens. Furthermore, we find that overexpressing E2F8 promotes, whereas silencing E2F8 suppresses, the proliferation and tumorigenicity of breast cancer cells both in vitro and in vivo. We further demonstrate that E2F8 transcriptionally upregulates CCNE1 and CCNE2 via directly interacting with their respective gene promoter, which accelerates the transition of $\mathbf{G 1}$ to $\mathbf{S}$ phase of breast cancer cells. Taken together, these findings uncover a novel biologic role and regulatory mechanism of E2F8 responsible for the progression of breast cancer, indicating E2F8 may represent a novel prognostic biomarker and therapeutic target against breast cancer.

\section{INTRODUCTION}

Sustaining proliferation is thought to be the most fundamental hallmark of cancer [1]. Generally, the production and release of proliferative signals that instruct entry into cell cycle progression are dysregulated in cancer cells, thereby breaking homeostasis of cell number and causing uncontrolled cell proliferation. During the cell cycle progression, G1/S phase transition emerges as one of the most critical steps, which involves activation of cyclin-dependent kinases (CDKs) by forming cyclinsCDK complex, phosphorylation of retinoblastoma $(\mathrm{Rb})$, and E2F-mediated gene transcription [2]. For instance, cyclin E (including cyclin E1 and cyclin E2) binds to $\mathrm{CDK} 2$, which in turn phosphorylates $\mathrm{Rb}$ to promote G1/S phase progression. Consistently, dysregulation of cyclin E-CDK2 activity is involved in various types of cancers, including breast, gastric, kidney and lung cancer, contributing to uncontrolled cell proliferation [3-7]. In fact, cyclin $\mathrm{E}$ is frequently amplified in breast cancer, and cyclin $\mathrm{E}$ overexpression is associated with a poor clinical benefit of breast cancer, while inhibition of cyclin E-CDK2 activity dramatically reduces proliferation and tumor formation and considered as a therapeutic approach 
in cancer [8-12]. Therefore, more detailed knowledge of cell cycle transition mechanisms would not only be beneficial to understanding the initiation and progression of breast cancer, but may also provide new clues for the development of novel therapeutic strategies.

The E2Fs (E2F1-E2F8) are a large family of transcription factors containing one or more conserved DNA binding domains (DBDs) that bind to target promoters and regulate their expressions [13]. E2F family transcription factors are critical for many developmental processes, and regulate cell cycle and DNA synthesis in mammalian cells. Notably, dysregulation of E2F proteins contribute to cancer initiation and progression. It was reported that ablation of E2F1, E2F3 or E2F4 in $\mathrm{Rb}^{+/-}$mice significantly suppressed the development of pituitary tumors, extending the tumor-free lifespan of $\mathrm{Rb}^{+/-}$mice [14-16]. In contrast, loss of E2F2 increased Myc-induced T cell lymphomagenesis in mice, and the reintroduction of E2F2 into E2F2-null tumors resulted in apoptosis of the tumor cells [17]. Moreover, E2F1-5, but not E2F6 or E2F7, are elevated and correlate with a higher proliferation index and a poorer clinical outcome in breast cancer [18-22]. Hence, these findings provide substantial evidence to demonstrate that E2Fs might function as a tumor suppressor or an oncogene during the progression and development of cancer. It has been reported that E2F8, in combination with E2F7, is required for embryonic development in mice $[23,24]$ and also angiogenesis [25] and lymphangiogenesis [26] in zebrafish. Interestingly, recent advances indicated that E2F8 is deregulated in several human cancers. Parisi et al. reported that the gene copy number of E2F8 was frequently gained in human melanoma [27]. Moreover, E2F8 has also been found to be overexpressed in ovarian cancer, hepatocellular carcinoma and lung cancer [28-30]. Reimer et al. found that overexpression of E2F8 was associated with histopathologic progression in ovarian cancer [28]. In addition, E2F8 promoted cancer cell proliferation, chemoresitance and invasion, and constituted a potential therapeutic target in hepatocellular carcinoma [29] and lung cancer [30]. Hence, these findings have provided substantial evidence that E2F8 may play a vital role in the malignant progression of cancer. However, the clinical significance and biological role of E2F8 during the progression of breast cancer remain to be elucidated.

In the present study, we show that E2F8 is markedly upregulated in human breast cancer and closely correlates with the clinicopathological features and prognosis of breast cancer. Overexpressing E2F8 dramatically promoted, whereas silencing E2F8 inhibited the proliferation and tumorigenicity of breast cancer cells both in vitro and in vivo. Furthermore, we demonstrate that E2F8 can promote entry into the G1/S phase of the cell cycle via transcriptionally upregulating cyclin E1 and cyclin E2 expression, thus contributing to cell proliferation and tumorigenicity in human breast cancer.
Taken together, our findings indicate that E2F8 plays an important role in the progression of human breast cancer and suggest that E2F8 may be a potential target for human breast cancer treatment.

\section{RESULTS}

\section{E2F8 is upregulated in breast cancer cell lines and tissues}

To investigate the clinical significance and biological role of E2F8 in breast cancer, we first analyzed the mRNA expression of E2F8 in breast cancer tissues with different molecular subtypes which show significant heterogeneity of breast cancer using published data from The Cancer Genome Atlas (TCGA) [31]. As shown in Figure 1A, E2F8 levels remained low in non-tumor breast tissues but became markedly higher in patients with luminal A and further elevated in other subtypes including luminal B, Basal-like and Her2-enriched, suggesting that $\mathrm{E} 2 \mathrm{~F} 8$ might contribute to high proliferation rates in breast cancer. Moreover, TCGA data analysis revealed that E2F8 levels were significantly upregulated in breast cancer tissues compared to paired tumor-adjacent nontumor tissues (Figure 1B). Furthermore, we verified E2F8 expression in breast cancer cell lines and fresh tissues. Real-time PCR and western blotting revealed that E2F8, at both the mRNA and protein levels, was markedly overexpressed in all 11 tested breast cancer cell lines than that in normal breast epithelial cells (NBEC1 and NBEC2) (Figure 1C and 1D). Similarly, the mRNA and protein levels of E2F8 were differentially upregulated in all 8 freshly-frozen breast cancer samples as compared to the matched adjacent non-tumor tissues (Figure 1E and 1F), suggesting that E2F8 is upregulated in breast cancer cell lines and breast cancer tissues.

\section{Upregulation of E2F8 correlates with progression and poor prognosis in breast cancer}

To evaluate whether E2F8 correlates clinically with breast cancer progression, the expression of E2F8 was examined by immunohistochemistry (IHC) in 187 paraffin-embedded, archived breast cancer tissues, including 33 cases of clinical stage I (17.6\%), 95 cases of stage II (50.8\%), 51 cases of stage III $(27.3 \%)$ and 8 cases of stage IV breast cancers (4.3\%) (Supplementary Table 1). Quantitative IHC analysis as determined by the mean optical density (MOD) showed that E2F8 expression increased along with disease stage in breast cancer $(P<0.05$, Figure 2A). In agreement with this observation, $\chi^{2}$ test revealed that E2F8 levels significantly correlated with the clinical stage, and TNM classifications in patients with breast cancer (all $P<0.05)$ (Supplementary Table 2), indicating a positive correlation between E2F8 expression and breast cancer progression. 
Furthermore, Kaplan-Meier and log-rank tests for survival analysis revealed that patients with high E2F8 expression had a significantly poorer overall survival compared to patients with low E2F8 expression $(P<0.001$; Figure 2B). Notably, E2F8 expression also significantly correlated with overall survival in breast cancer patients

A

TCGA BRCA dataset

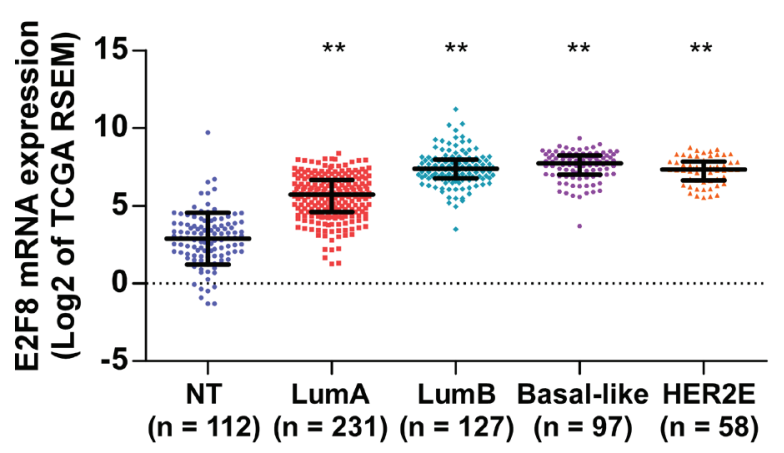

with clinical stage $1+2$ subgroup ( $n=128, P=0.001$; Figure 2C), as well as clinical stage $3+4$ subgroup ( $n=59, P=0.039$; Figure 2D), suggesting that E2F8 might be a valuable prognostic marker for breast cancer patients at all disease stages. Interestingly, assessment from a publicly available breast cancer microarray data KM

C

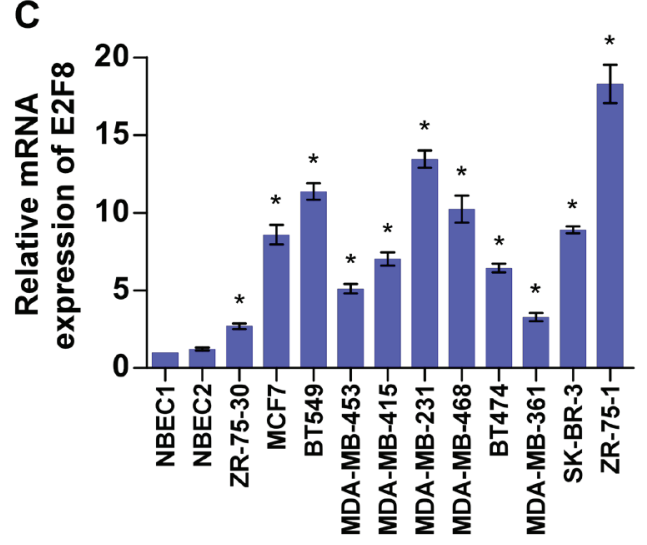

D

B

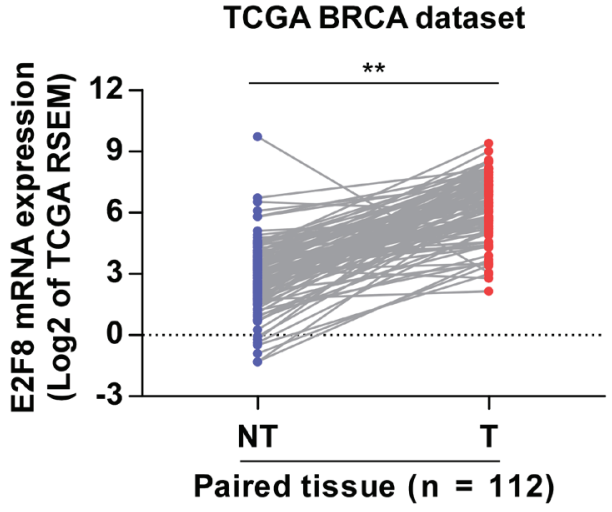

E

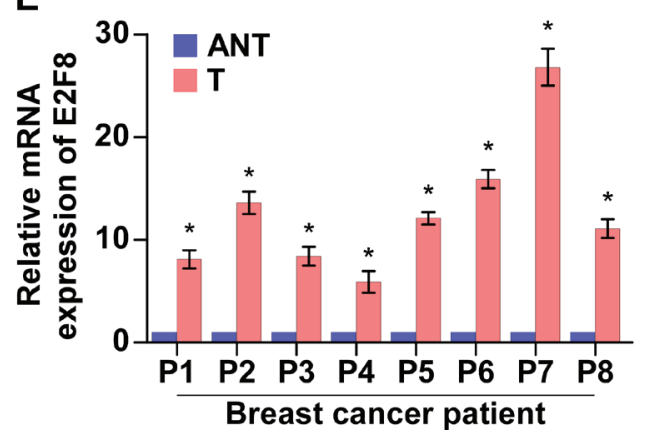

$\mathbf{F}$

\section{Breast cancer patient}

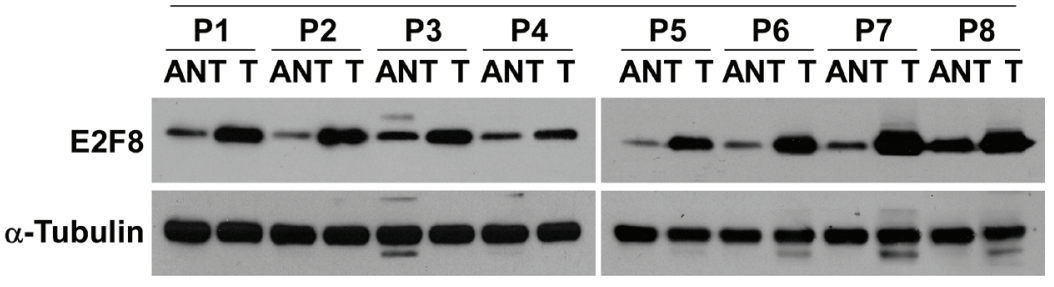

Figure 1: E2F8 is overexpressed in breast cancer cell lines and tissues. (A and B) E2F8 mRNA levels in breast cancer tissues were assessed by analyzing TCGA breast cancer mRNA data set (A) (NT (non-tumor), $n=112$; LumA (luminal A), $n=231$; LumB (luminal B), $n=127$; Basal-like, $n=97$; HER2E (Her2-enriched), $n=58$ ) and (B) the 112 paired adjacent non-tumor tissues (NT) and breast cancer tissues (T). Data were acquired from the TCGA data portal (https://tcga-data.nci.nih.gov/tcga/tcgaHome2.jsp). Lines represent mean \pm SD. ${ }^{* * P}<0.001$, $t$-test. (C and D) Real-time PCR (C) and Western blotting (D) analyses detecting the mRNA and protein levels of E2F8 expression in two preparations of normal human breast epithelial cells (NBEC1 and NBEC2) and cultured breast cancer cell lines. (E and $\mathbf{F}$ ) Real-time PCR (E) and Western blotting (F) analyses of E2F8 mRNA and protein expression in paired primary breast cancer tissues (T) and the matched adjacent non-tumor tissues (ANT) from eight breast cancer patients (P1-P8); mRNA expression was normalized to GAPDH and $\alpha$-tubulin was used as a protein loading control. Data are mean $\pm \mathrm{SD}$ of three independent experiments; $* P<0.05$. 
plotter [32] has shown a significant correlation between high expression of E2F8 and poor overall survival, relapse-free survival and distant metastasis-free survival of breast cancer patients (Supplementary Figure 1). Univariate and multivariate analyses indicated that clinical stage and expression of E2F8 and Ki67 were independent prognostic factors (Supplementary Table 3), which further supported the notion that E2F8 expression might represent a novel prognostic biomarker for the disease.

\section{Upregulation of E2F8 promotes proliferation of breast cancer cells}

The biological role of E2F8 in breast cancer was further explored using Gene Set Enrichment Analysis (GSEA) [33] based on mRNA expression data from the TCGA, which indicated that high levels of E2F8 correlated significantly with proliferation-associated gene signature (Figure 3A). Moreover, E2F8 expression levels were positively correlated with $\mathrm{Ki} 67$ expression from both TCGA mRNA data set $(r=0.817, P<0.001)$ and our IHC results $(P<0.001)$ (Figure 3B, 3C), suggesting that E2F8 may contribute to cell proliferation in breast cancer.
We then evaluated the role of E2F8 in breast cancer cell proliferation by stably exogenously overexpressing, or endogenously knocking down of E2F8 expression via retrovirus infection (Figure 3D). An MTT assay showed that overexpression of E2F8 increased, while depletion of E2F8 expression reduced proliferation rates of both MCF7 and SK-BR-3 breast cancer cell lines (Figure 3E). Similar results were obtained in the colony formation assay (Figure 3F). Taken together, these data suggest that E2F8 plays important roles to promote breast cancer cell proliferation and colony formation in vitro.

\section{Upregulation of E2F8 enhances tumorigenicity of breast cancer cells}

Since E2F8 expression was correlated with the clinical staging and TNM classification of breast cancer (Supplementary Table 2), we further evaluated the effect of E2F8 on the tumorigenic activity of breast cancer cells. First, we found that the anchorage-independent growth abilities of both MCF7 and SK-BR-3 breast cancer cell lines were significantly increased by overexpressing E2F8, but reduced by silencing E2F8 (Figure 4A).

A
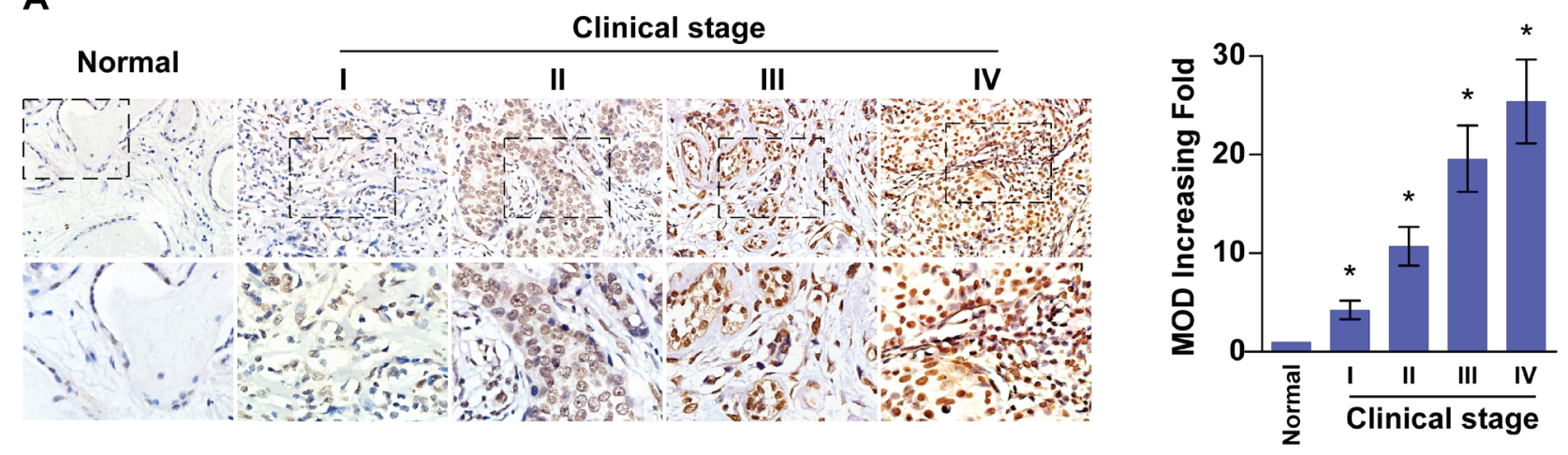

B

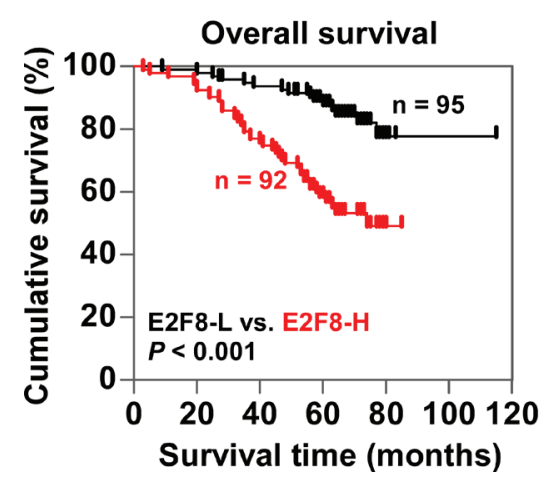

C

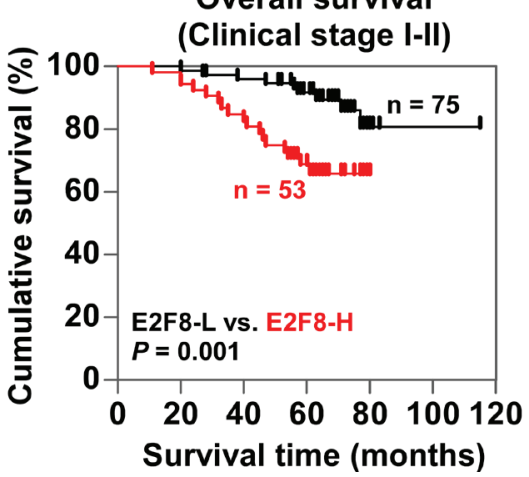

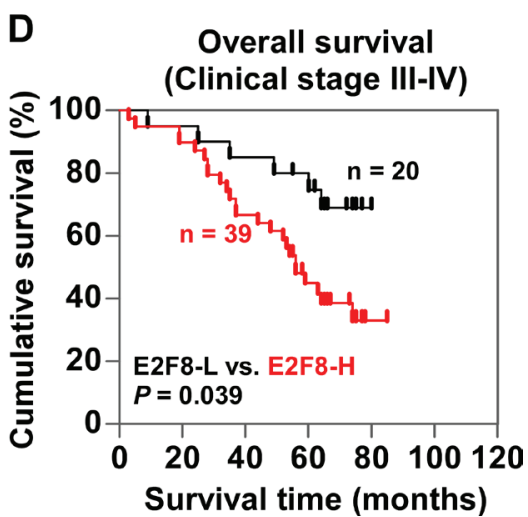

Figure 2: Upregulation of E2F8 correlates with progression and poor prognosis in breast cancer. (A) Left panel: representative IHC analyses of E2F8 expression in normal breast tissue and breast cancer specimens of different clinical stages. Right panel: Statistical quantification of the mean optical density (MOD) of E2F8 staining between normal breast tissues and breast cancer specimens. ${ }^{*} P<0.05$. (B) Kaplan-Meier analysis of overall survival curves for breast cancer patients with low E2F8 expression (E2F8-L; $n=95)$ versus high E2F8 expression (E2F8-H; $n=92)(n=187 ; P<0.001$, log-rank test). (C and D) E2F8 expression also significantly correlated with overall survival in breast cancer patients with clinical stage $1+2$ subgroup $(n=128 ; P=0.001$, log-rank test $)$, or clinical stage $3+4$ subgroup $(n=59 ; P=0.039$, log-rank test $)$. 
Furthermore, the transwell assay showed that silencing of E2F8 dramatically reduced the invasion capability of basal-like breast cancer cells MDA-MB-231 and BT549 (Supplementary Figure 2), suggesting that E2F8 expression played an important role in the invasive phenotypes of basal-like breast cancer cells.
Moreover, the role of E2F8 in the tumorigenicity of breast cancer cells was further determined in vivo. As shown in Figure 4B-4E, the E2F8-overexpressing tumors grew at a much higher rate in terms of size and weight, than the control tumors, whereas the tumors formed by E2F8-silenced cells were smaller and had
A

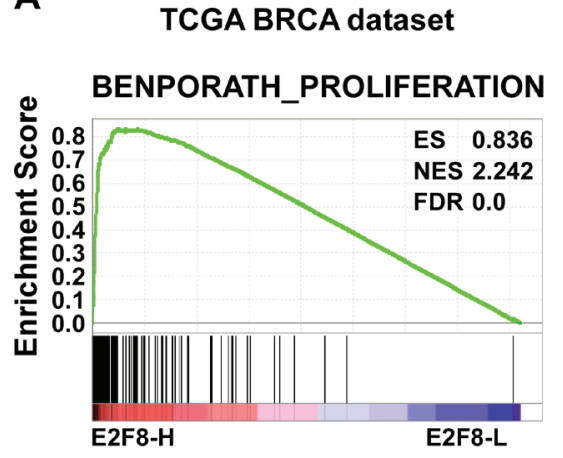

D

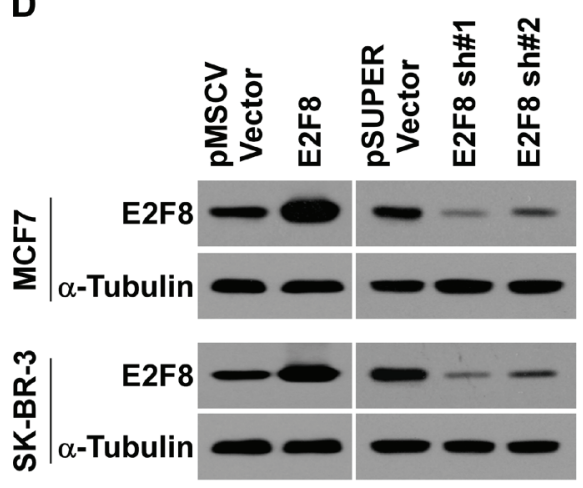

B

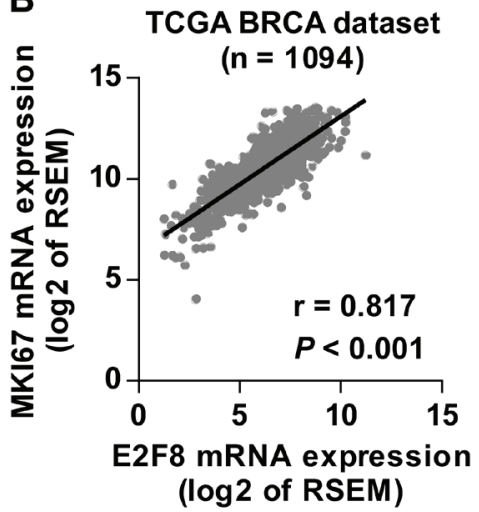

E

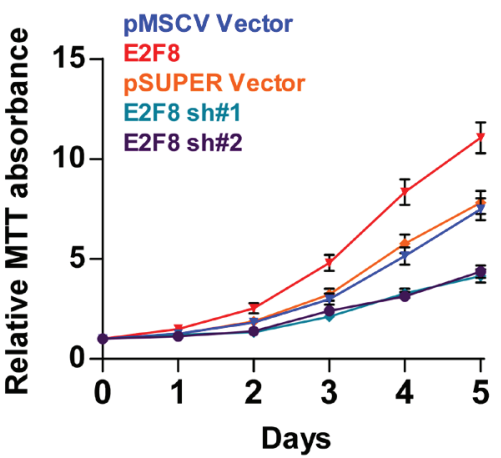

C
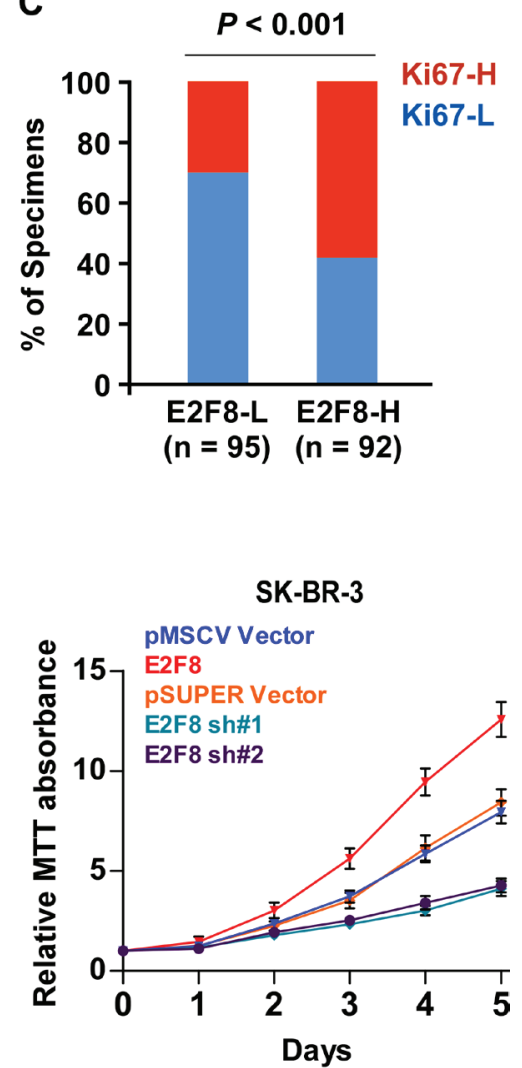

$\mathbf{F}$
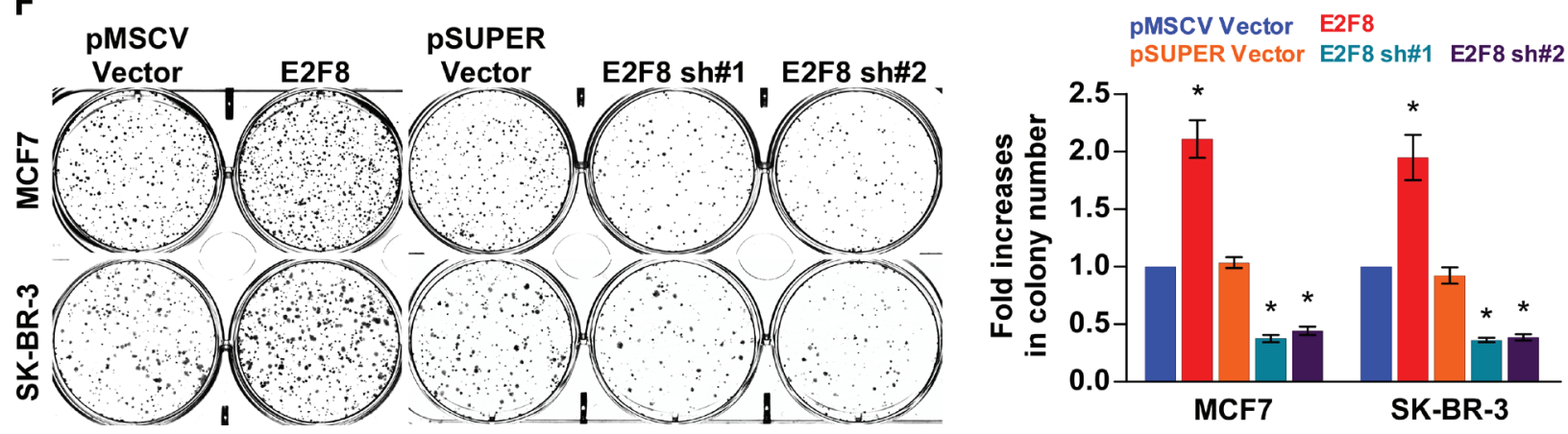

Figure 3: Upregulation of E2F8 promotes proliferation of breast cancer cells. (A) GSEA plot performed using GSEA v2.2.0 (http://www.broadinstitute.org/gsea/) showed that high E2F8 expression was positively correlated with the cell cycle-associated gene signature (BENPORATH_PROLIFERATION) based on TCGA BRCA mRNA data set. (B) Correlations between E2F8 and MKI67 mRNA expression based on TCGA BRCA mRNA data set. r, Pearson correlation coefficient; $P<0.001$. (C) The protein expression levels of E2F8 were associated with the expression of Ki67 in 187 primary breast cancer specimens. Percentage of specimens showing low or high Ki67 expression (Ki67-L and Ki67-H) in 187 primary human breast cancer specimens, related to the levels of E2F8. $P<0.001, \chi^{2}$ test. (D) Western blotting analysis of E2F8 protein expression in the constructed MCF7 and SK-BR-3 cells; $\alpha$-tubulin was used as a loading control. (E) Proliferation rate of the indicated breast cancer cells, as determined using the MTT assay. (F) Representative images (left panel) and quantification (right panel) of crystal violet-stained colony formation for the indicated cell lines. Data are mean \pm SD of three independent experiments. $* P<0.05$. 
lower tumor weights than the tumors formed from shRNA-vector control cells. Expression levels of E2F8 in xenografts were further examined by western blotting. E2F8 was robustly upregulated in tumors formed by SKBR-3/E2F8 cells, but downregulated in tumors formed by E2F8-silencing SK-BR-3 cells (Supplementary Figure 3). Furthermore, IHC analysis revealed that E2F8overepressing tumors displayed higher $\mathrm{Ki} 67$ proliferation index, whereas E2F8-silenced tumors showed reduced numbers of Ki67 positive cells (Figure 4F). Taken together, these results suggest that E2F8 promotes the tumorigenicity of breast cancer cells in vivo.

\section{E2F8 promotes the G1/S phase transition of breast cancer}

We then explored the mechanism underlying the promotion of cellular proliferation by E2F8. GSEA results indicated that high E2F8 expression was significantly correlated with the cell cycle-associated gene signatures, suggesting that E2F8 is involved in the cell cycle regulation (Figure 5A). Moreover, overexpression of E2F8 resulted in a significant increase in the percentages of cells in the $\mathrm{S}$ peak, but a decrease in the percentages of cells in the G0/G1 peak, whereas silencing E2F8 had the opposite
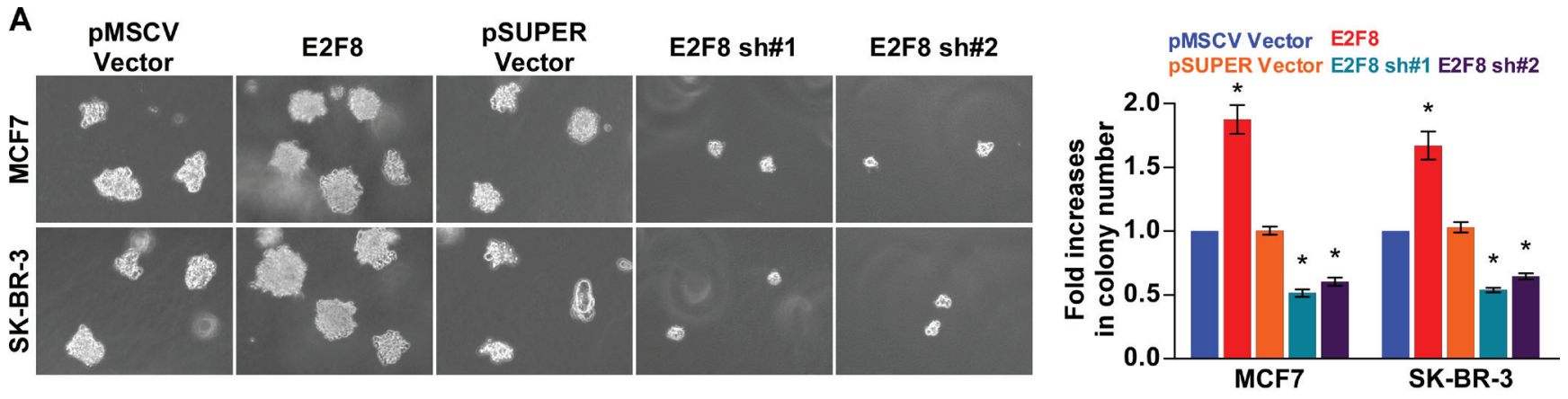

B

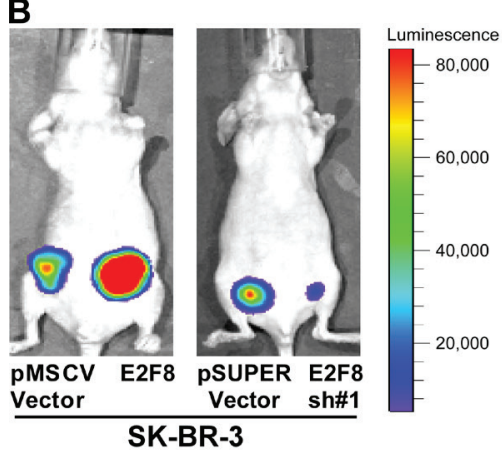

C

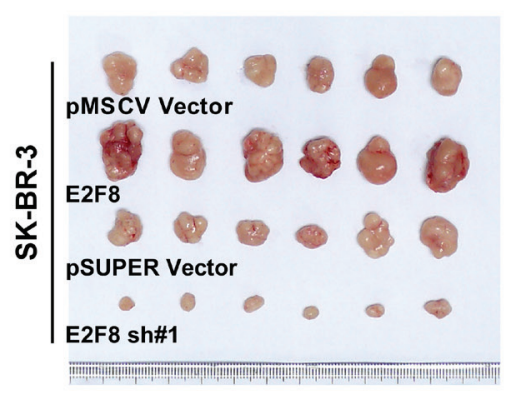

D

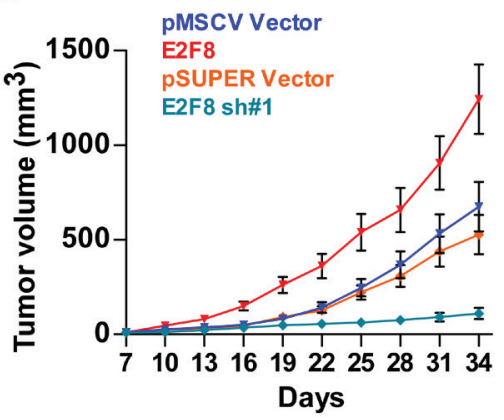

E

pMSCV Vector E2F8 pSUPER Vector E2F8 sh\#1

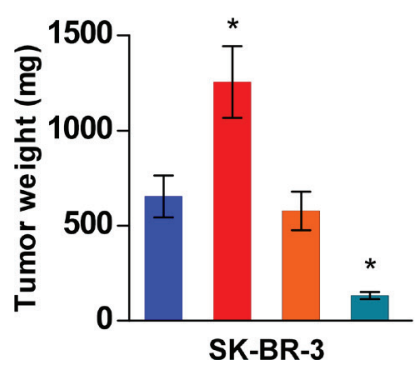

$\mathbf{F}$

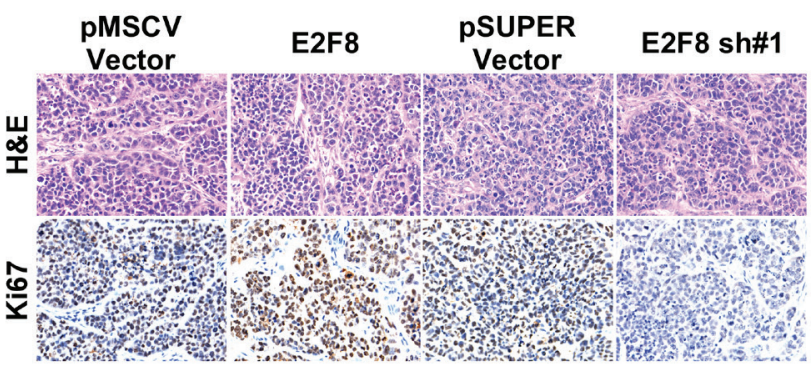

pMSCV Vector E2F8 pSUPER Vector E2F8 sh\#1

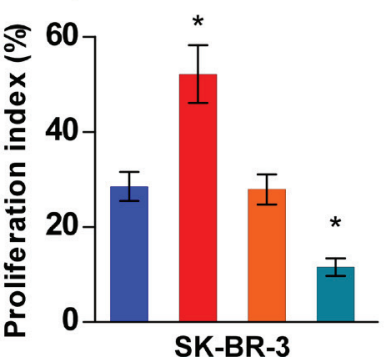

Figure 4: Upregulation of E2F8 enhances breast cancer cell tumorigenicity. (A) Representative micrographs (left panel) and quantification (right panel) of colonies determined by anchorage-independent growth assay. Colonies larger than $0.1 \mathrm{~mm}$ in diameter were scored. (B) Xenograft model in nude mice. Representative images of tumor-bearing mice (B) and tumors (C) from each experimental group. (D) Volumes of tumors in the E2F8-overexpressing, E2F8-silencing, and control groups were measured on indicated days. Data presented are the mean \pm SD. (E) Tumor weights of each group. (F) Proliferation index (right) was determined using the percentage of Ki67-positive cells (left). Data are mean \pm SD of three independent experiments. ${ }^{*} P<0.05$. 
effects (Figure 5B). Similarly, a BrdU incorporation assay revealed that the percentages of cells with incorporated BrdU was significantly enhanced in E2F8-overexpressing cells and reduced in E2F8-silenced cells (Figure 5C). Thus, these results indicate that E2F8 promotes cell cycle progression of breast cancer cells, confirming that E2F8 promotes breast cancer cell proliferation.

\section{E2F8 directly enhances the promoter activities of cyclin E1 and cyclin E2}

Since E2F8 is involved in the cell cycle regulation of breast cancer cells, we examined the expression of cell cycle regulators. As shown in Figure 6A and 6B, real-time PCR and western blotting analysis revealed that multiple cell cycle regulators, especially CCNE1 and CCNE2, were robustly increased in E2F8-overexpressing cells, but reduced in E2F8-silenced cells compared to control cells. Consistent with this observation, correlation analysis in TCGA Breast Invasive Carcinoma (BRCA) data set reveals that E2F8 positively correlates with Cyclin E1 and Cyclin E2 (Supplementary Figure 4). Moreover, phosphorylation of $\mathrm{Rb}$, the downstream target protein of cyclin E-CDK2 complex, was shown to be induced in E2F8-overexpressing cells, but suppressed in the E2F8silenced cells (Figure 6B).
A
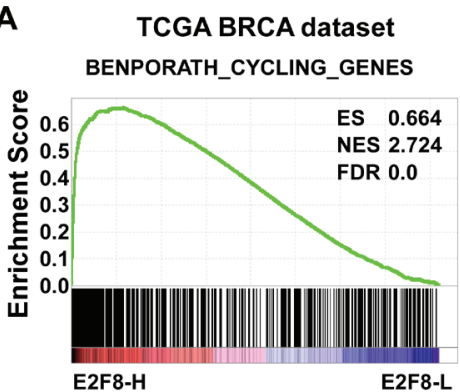

TCGA BRCA dataset REACTOME_DNA_REPLICATION

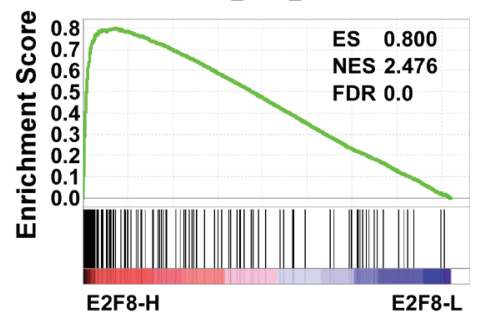

TCGA BRCA dataset

REACTOME_MITOTIC_G1_G1_S_PHASES

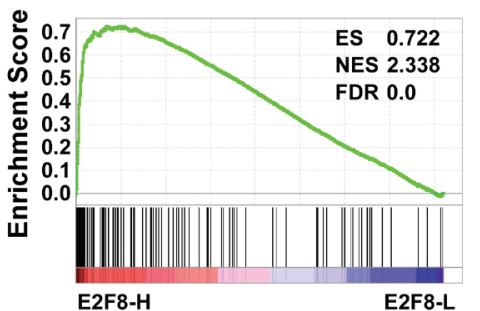

B
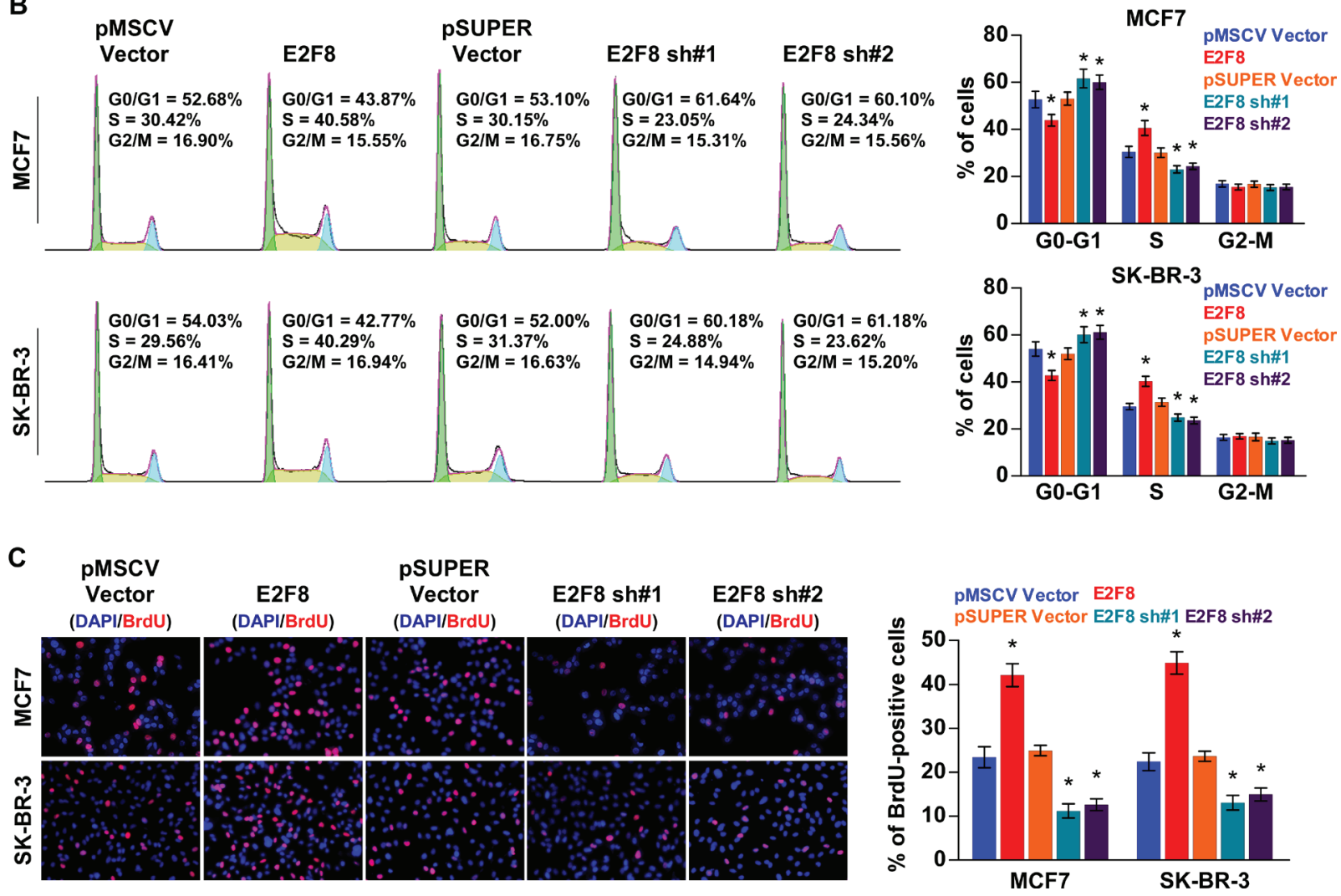

Figure 5: E2F8 promotes the cell cycle in breast cancer. (A) GSEA results indicated that E2F8 expression was significantly correlated with the cell cycle-associated gene signatures including BENPORATH_CYCLING_GENES, REACTOME_DNA_ REPLICATION, and REACTOME_MITOTIC_G1_G1_S_PHASES. (B) Flow cytometric analysis of indicated breast cancer cells. (C) Representative micrographs (left panel) and quantification (right panel) of BrdU incorporation in the indicated breast cancer cells. DAPI was used as a DNA/nuclear stain. 
Interestingly, by analysis of the promoter regions of CCNE1 and CCNE2 using the ConSite [34] and Genome Browser Gateway website programs, we found multiple typical response elements of E2F transcription factor, suggesting that E2F8 might induce CCNE1 and CCNE2 expression by directly targeting their gene promoters. As expected, luciferase reporter assays revealed that overexpression of E2F8 activated, whereas downregulation of E2F8 attenuated, the luciferase activity of CCNE1 and CCNE2 promoters in breast cancer cells in a dose-dependent manner (Figure 6C, 6D). ChIP assays showed that E2F8 was capable of binding to different fragment regions within the CCNE1 and CCNE2 promoters (Figure 6C, 6D and Supplementary Figure 5A). To validate this, we performed ChIP assays by pulling downing transcription activation marker H3K27Ac. Immunoprecipitation with anti-H3K27Ac Ab significantly enriched for CCNE1 and CCNE2 (Supplementary Figure 5B), confirming CCNE1 and CCNE2 is a direct E2F8 target. Collectively, these results demonstrate that E2F8 can upregulate cyclin E1 and cyclin E2 in breast cancer by binding to the promoter of the CCNE1 and CCNE2 genes to activate their transcription.

\section{Clinical relevance of E2F8-induced cyclin E1 and cyclin $\mathrm{E} 2$ in human breast cancer}

Finally, we examined whether E2F8-mediated cyclin $\mathrm{E} 1$ and cyclin E2 activation in breast cancer cells was clinically relevant. As shown in Figure 7A and 7B, E2F8 levels in 10 freshly collected breast cancer samples were significantly positively correlated with levels of cyclin E1 $(r=0.723, P=0.018)$, cyclin E2 $(r=0.803, P=0.005)$, and phosphorylation level of $\mathrm{Rb}(r=0.639, P=0.047)$. Collectively, these results further support the notion that upregulation of E2F8 contributes to uncontrolled cell proliferation and tumorigenecity, resulting in poor clinical outcome in breast cancer.

\section{DISCUSSION}

E2F proteins have been proved to be important regulators of many processes relevant to cancer. For instance, the most studied member E2F1 maintained centrosome amplification and inhibited the promoter activity of the tumor suppressor gene ARHI, contributing to the tumorigenesis of breast cancer [18, 19]. Newly identified E2F8 acts as a potent cell cycle regulator, and has been emerging as a critical proliferation promoter in several human cancers [28-30]. However, the clinical significance and biological role of E2F8 in breast cancer remain largely unknown. This study establishes a vital role for E2F8 as a promoter of breast cancer proliferation and tumorigenecity. Significantly, we found that E2F8 was upregulated and correlated with clinical progression and poor prognosis in human breast cancer. Furthermore, our results reveal a potential molecular mechanism by which E2F8 promotes cell proliferation and tumorigenicity in breast cancer, via transcriptionally activating the CCNE1, and CCNE2 promoters. Taken together, these findings provide strong evidence that upregulation of E2F8 plays important roles in promoting breast cancer progression, and E2F8 might represent a novel prognostic biomarker and therapeutic target for the disease.

Based on gene expression profiles and genomic characterization, four main breast cancer subtypes have been proposed: luminal A, luminal B, HER2-enriched and basallike $[35,36]$. Subtype information has been shown to be an independent predictor of survival in breast cancer, where the luminal A subtype has a favorable prognosis compared to other subtypes [37]. The luminal B, basal-like and Her2-enriched subtypes include a characteristic signature containing high expression of genes associated with cell proliferation whereas luminal A has a low proliferation rate; however the mechanism remains unclear [31]. Herein, we found that E2F8 was further elevated in luminal B, basallike and Her2-enriched subtypes than luminal A. E2F8 expression levels positively correlated with the proliferation marker Ki67 in patient tissues and in vivo tumor models. Thus, our findings suggest that E2F8 contributes to the proliferation capabilities in different breast cancer subtypes.

The functions of E2F8 on cell cycle progression and tumorigenesis in breast cancer are still unclear. In the present work, overexpression of E2F8 induced the expression of multiple cell cycle regulators, and upregulated cylin E1 and cyclin E2 by directly targeting their promoter elements, leading to G1/S phase transition and high cell proliferation rate. The CDK2-cyclin E complex was well known as they play an important role in tumor development through regulation of the cell cycle [38-40]. The expression of cyclin E1 (CCNE1) and cyclin E2 (CCNE2) was found to be strongly activated by the E2F transcription factors, such as E2F1 [41, 42], and the CDK2-cyclin E complex phosphorylated and inactivated $\mathrm{Rb}$, while the phosphorylated $\mathrm{Rb}$ released E2F transcription factors, thereby promoting cell-cycle progression from $\mathrm{G} 1$ to $\mathrm{S}$ phase led to tumor regressions [43-45]. Thus, it would be of great interest and importance to investigate whether E2F8 upregulates cyclin E1, and cyclin E2 expression induce proliferation and tumorigenesis in breast cancer via Rb-E2F pathway which is critical in regulating in initiation of DNA replication.

The E2F proteins are conventionally considered to function as either activators (E2F1-3a) or repressors (E2F3b-8) of transcription during cell cycle regulation [46]. E2F8 was initially found to act as a repressor, as downregulated E2F-target genes blocked cell-cycle progression in fibroblasts $[47,48]$. However, emerging evidence has revealed that E2F family members can function as either transcription activators or repressors, depending on the cellular and tissue context, or target genes [49-52]. Interestingly, E2F8 stimulate 
A

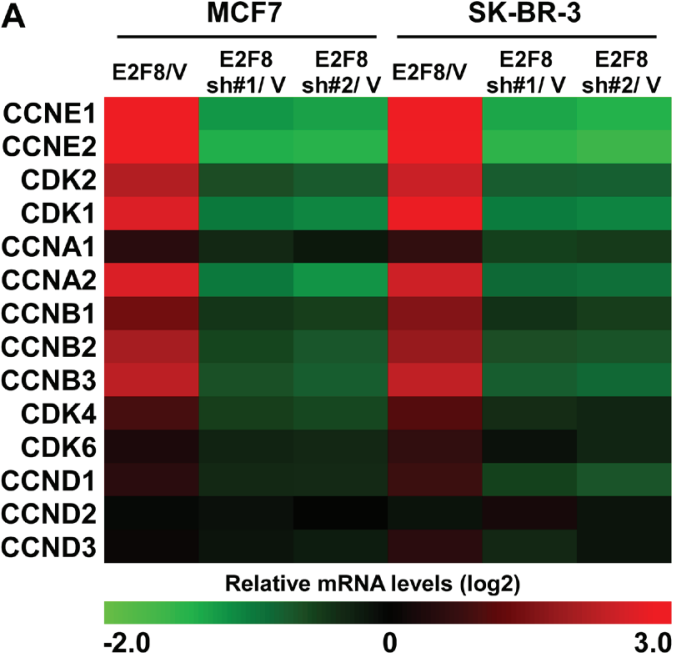

B

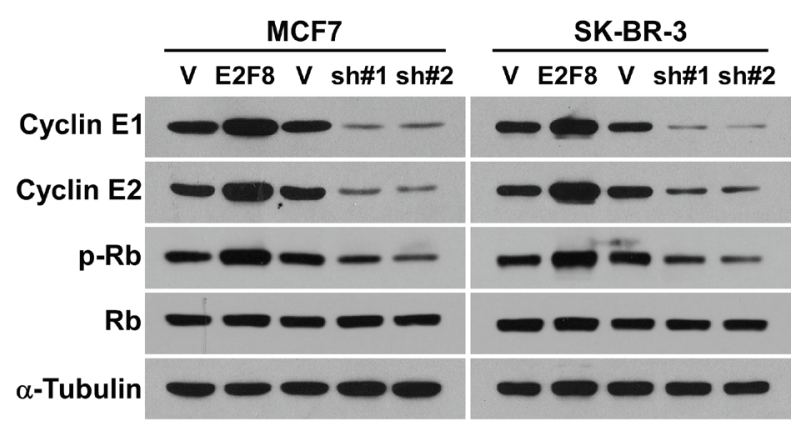

C
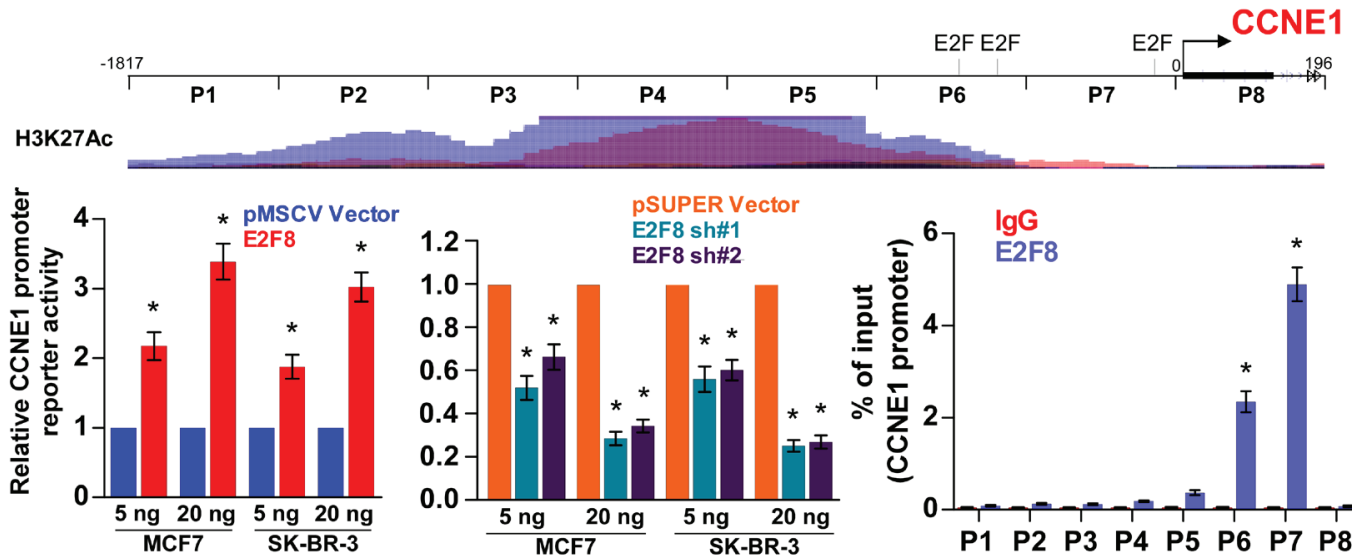

$-1$
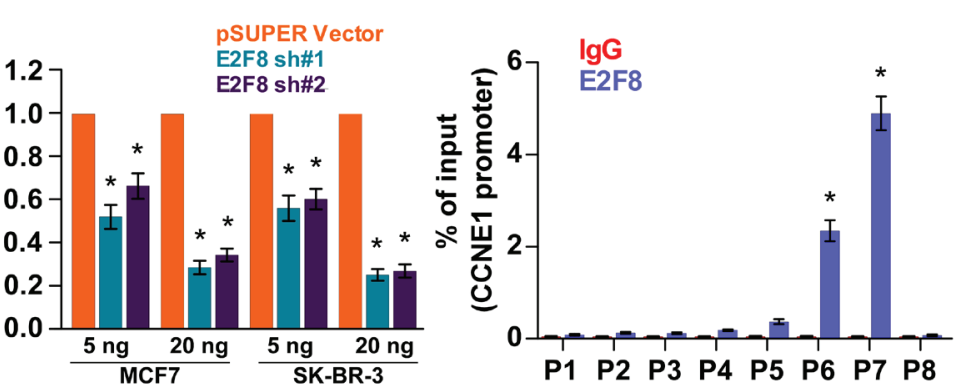

D

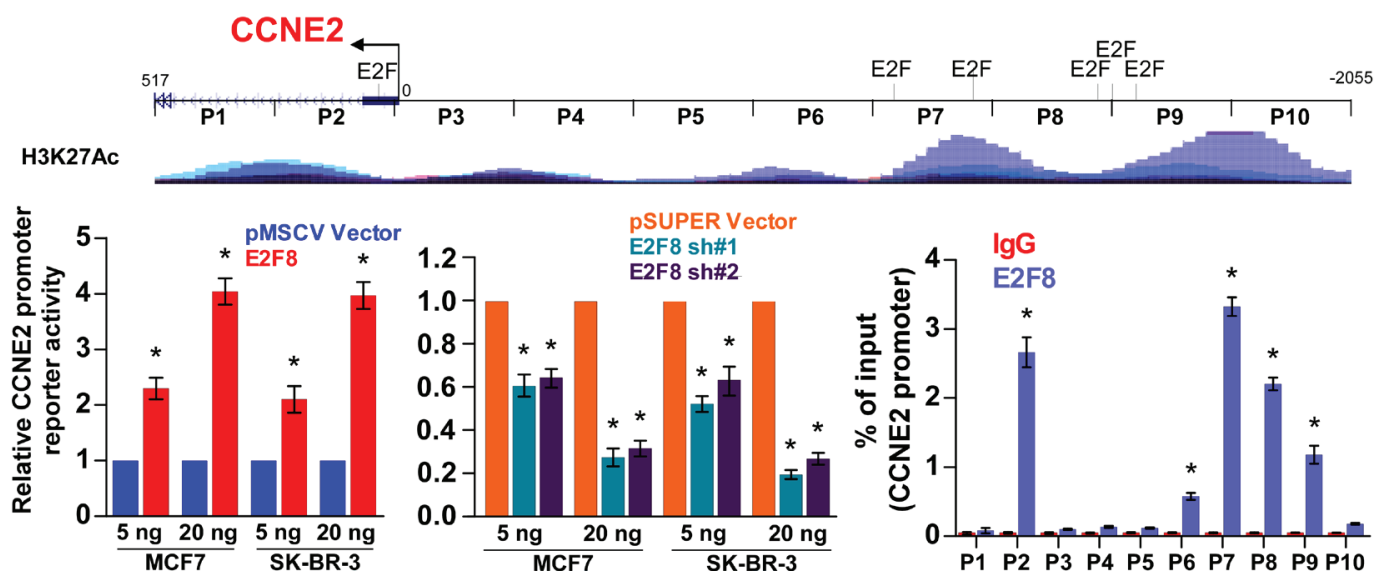

Figure 6: E2F8 directly upregulates the promoter activities of cyclin E1 and cyclin E2. (A) Real-time PCR analysis of cell cycle-related genes mRNA expression in the indicated cells. Gene expression levels were normalized to GAPDH. The pseudocolours represent the intensity scale of E2F8 versus pMSCV vector (V) or E2F8 sh\#1/2 versus pSUPER vector (V), generated by log2 transformation. (B) Western blotting analysis of cyclin E1, cyclin E2, phosphorylated $\mathrm{Rb}(\mathrm{p}-\mathrm{Rb})$ and total Rb protein expression in the indicated cells; $\alpha$-tubulin was used as a loading control. (C and D) Upper panel: Schematic illustration of ChIP PCR fragments for the indicated nucleotide regions of the CCNE1 (C) and CCNE2 (D) promoters. Multiple typical response elements of E2F transcription factor were predicted using the ConSite program. H3K27Ac enrichment, indicating high transcription activity, is observed in the promoter elements according to Genome Browser Gateway website. Left panel: Luciferase activity assays in MCF7 and SK-BR-3 cells showed transactivation of the CCNE1 and CCNE2 promoters by E2F8 overexpression and repression by E2F8 silencing. Right panel: ChIP enrichment assay confirms that E2F8 binds to the predicted promoter site of CCNE1 and CCNE2; IgG was used as a negative control. Results were evaluated from three independent experiments, ${ }^{*} P<0.05$. 
transcriptional activation of VEGFA in hypoxic cells, and on the other hand E2F8 repressed transcription of VEGFR1/2 in endothelial cells $[25,53]$. E2F8 directly stimulate the CCBE1 promoter activity, but silence the promoter of FLT4 to control lymphangiogenesis during zebrafish embryonic development [26]. In addition, E2F8 was reported to transcriptionally upregulate cyclin D1 in hepatocellular carcinoma [29], and UHRF1 in lung cancer [30]. Thus, these recent advances indicate that E2F8 regulates a variety of downstream genes in a context-dependent manner. Herein, we report that E2F8 upregulates cyclin E1 and cyclin E2 expression by directly binding to these genes promoters, further supporting the notion that E2F8 promotes breast cancer proliferation and tumorigenicity by upregulating multiple cell cycle regulators. Considering that $\mathrm{E} 2 \mathrm{~F} 8$ is identified to activate the VEGFA promoter through cooperation with other transcriptional activator HIF1 [25], or the cyclin D1 promoter by blocking the occupancy of other E2Fs [29], it would be of great interest to investigate whether E2F8 may regulate $\mathrm{CCNE} 1$, and $\mathrm{CCNE} 2$ gene expression in breast cancer by either cooperating with other transcriptional activators or blocking the occupancy of other E2Fs.

In summary, our study has revealed that E2F8 upregulation plays an important role in breast cancer progression and E2F8 is a critical cell cycle promoter by directly upregulating CCNE1, and CCNE2. Understanding the precise role of E2F8 in breast cancer pathogenesis and in the cell cycle regulation promises to increase our knowledge of the biological basis of cancer development and may also facilitate the development of new therapeutic strategies against breast cancer.

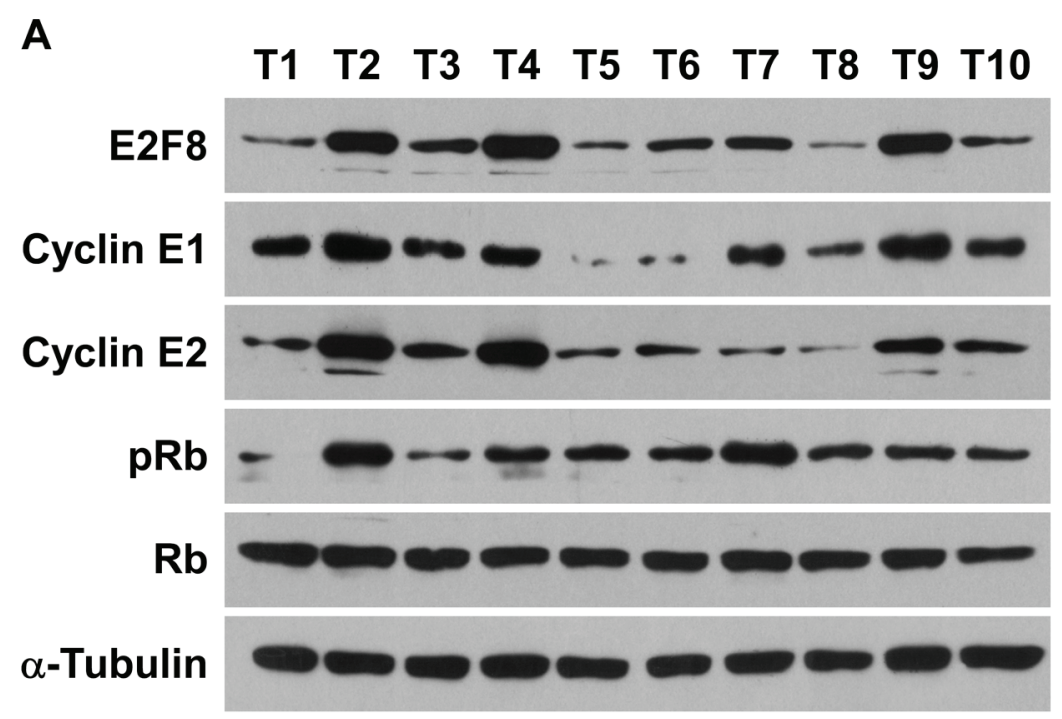

B
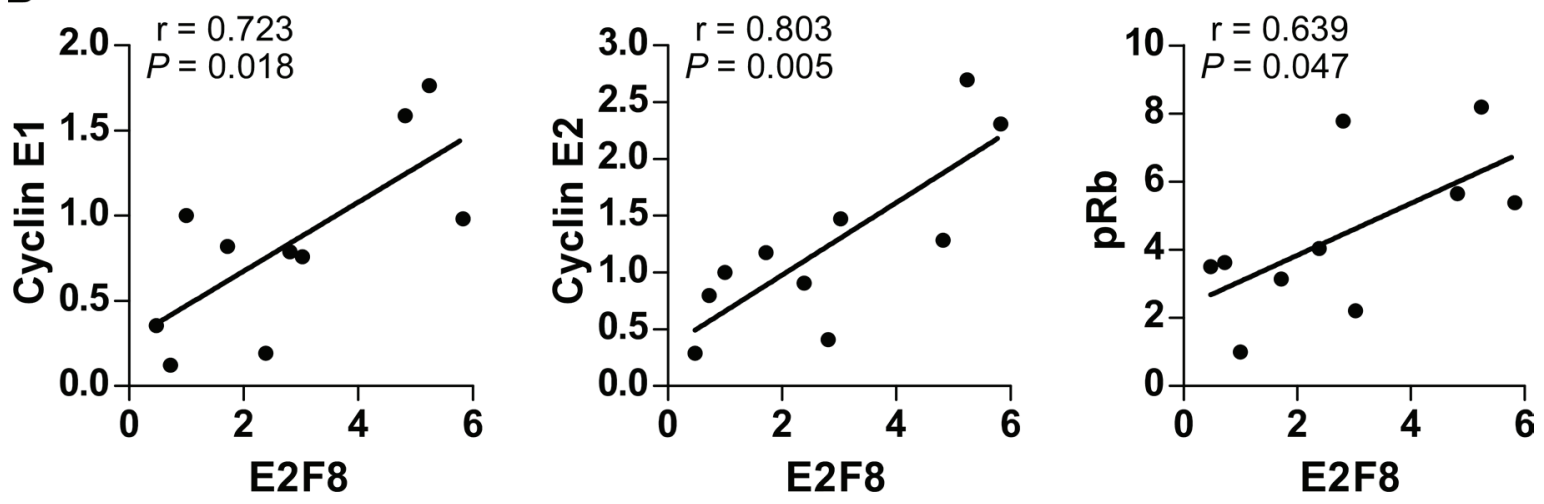

Figure 7: Relevance of E2F8-induced cyclin E1 and cyclin E2 activation in human cancers. (A) Western blotting assay showing that the protein expression of E2F8, cyclin E1, cyclin E2, p-Rb and total Rb in 10 breast cancer samples. $\alpha$-Tubulin was used as the loading controls. (B) Correlation analysis of E2F8 and cyclin E1, cyclin E2 and p-Rb expression, respectively. The expression levels of E2F8, Cyclin E1 and Cyclin E2 were determined by densitometry. The ratio of first sample (E2F8/ $\alpha$-tubulin, Cyclin E1/ $\alpha$-tubulin, Cyclin E2/ $\alpha$-tubulin) was considered as 1.0. $r$, Pearson correlation coefficient. 


\section{MATERIALS AND METHODS}

\section{Cell lines and cell culture}

Primary normal breast epithelial cells (NBEC1 and NBEC2) were established from the mammoplasty materials of two women at the Department of Plastic Surgery, the First Affiliated Hospital of Sun Yat-sen University, according to the rules and regulations relating ethical issues on research use of human subjects in China, as described previously [54]. Breast cancer cell lines (ZR-75-30, MCF7, BT549, DA-MB-453, MDAMB-415, MDA-MB-231, MDA-MB-468, BT474, MDAMB-361, SK-BR-3, and ZR-75-1) were obtained from American Type Culture Collection (ATCC) and cultured in the Dulbecco's Modified Eagle Medium (DMEM) (Invitrogen) with 10\% fetal bovine serum (HyClone) at $37^{\circ} \mathrm{C}$ in a $5 \% \mathrm{CO}_{2}$ atmosphere.

\section{Patients and tissue specimens}

A total of 187 paraffin-embedded breast cancer specimens were collected for this study, which had been diagnosed histopathologically at the Sun Yat-sen University Cancer Center from 2002 to 2007. Clinical information of the samples is described in detail in Supplementary Table 1 . The fresh tissues including eight paired breast cancer tissues and adjacent non-tumor tissues and ten breast cancer tissues were obtained from individuals who were diagnosed with breast cancer. Prior patient's consents and approval from the Institutional Research Ethics Committee were obtained to use these clinical specimens for research purposes.

\section{Western blotting analysis}

Western blotting analysis was performed as described previously [54]. Briefly, cell were harvested in lysis buffer $[25 \mathrm{mmol} / \mathrm{L}$ Tris ( $\mathrm{pH}$ 6.8), 1\% SDS, $5 \mathrm{mmol} / \mathrm{L}$ EDTA, protease inhibitor cocktail (Sigma)]. Protein concentration was determined with the bicinchoninic acid (BCA) assay (Pierce, Rockford, USA) according to the manufacturer's instructions. An anti-E2F8 mouse monoclonal antibody (1:1000 dilution; Abnova), an anticyclin E1 mouse monoclonal antibody (1:1000 dilution; Proteintech), an anti-cyclin E2 mouse monoclonal antibody (1:1000 dilution; Proteintech), an anti-Rb mouse monoclonal antibody (1:2000 dilution; Cell Signaling Technology), an anti-p-Rb rabbit polyclonal antibody (1:1000 dilution; Cell Signaling Technology), an anti$\alpha$-tubulin mouse monoclonal antibody (1:5000 dilution; Sigma) and the second antibody, goat anti-mouse immunoglobulin G (1:2000 dilution; Pierce), were used in this study.

\section{Immunohistochemistry}

Immunohistochemistry (IHC) analysis was performed on the 187 paraffin-embedded breast cancer tissue sections as previously described [55]. The degree of immunostaining of formalin-fixed, paraffin-embedded sections were reviewed and scored separately by two independent pathologists. The scores were determined by combining the proportion of positively-stained cells and the intensity of staining. Cell proportions were scored as follows: 0 , no positive cells; $1,<10 \%$ positive cells; $2,10 \%-35 \%$ positive cells; $3,35 \%-75 \%$ positive cells; $4,>75 \%$ positive cells. Staining intensity was graded according to the following standard: 1, no staining; 2, weak staining (light yellow); 3, moderate staining (yellow brown); 4, strong staining (brown). The staining index (SI) was calculated as the product of the staining intensity score and the proportion of positive cells. Using this method of assessment, we evaluated protein expression by determining the SI, with possible scores of $0,2,3,4,6,8,9,12$, and 16 . Samples with a SI $\geq 8$ were determined as high expression and samples with a $\mathrm{SI}<8$ were determined as low expression. Cutoff values were determined on the basis of a measure of heterogeneity using the log-rank test with respect to overall survival.

The method of MOD was used to determine the immunostaining intensity of each tested specimen and performed as previously reported [56]. Briefly, the stained sections were evaluated at $\times 200$ magnification, and 10 representative staining fields of each section were analyzed to verify the MOD, which represents the strength of staining signals as measured per positive pixels. The MOD data were statistically analyzed using $t$-test to compare the average MOD difference between different groups of tissues, and $P<0.05$ was considered significant.

\section{Plasmids, virus constructs and retroviral infection of target cells}

Human CCNE1 and CCNE2 promoters were cloned, respectively, into the pGL3 luciferase reporter plasmid (Promega, Madison, WI, USA). Transfection of luciferase reporter plasmids was performed using the Lipofectamine 3000 reagent (Invitrogen) according to the manufacturer's instruction. Human E2F8 cDNA was PCR-amplified and cloned into the pMSCV-puro-retro vector (Clontech). Two short-hairpin RNA (shRNA) against E2F8 in pLKO-puro vector were commercially purchased (Sigma-Aldrich). Luciferase cDNA was PCR-amplified and cloned into the pMSCV-neo-retro vector (Clontech). Cells $\left(2 \times 10^{5}\right)$ were seeded and infected by retroviral generated by pMSCVpuro-E2F8 or pLKO-puro-E2F8-shRNA transfecting in 293FT for 3 days. All these cells were further transfected with pMSCV-neo-luci plasmid. The stable cell lines 
expressing E2F8-luci and E2F8-shRNA-luci were elected with $0.5 \mu \mathrm{g} / \mathrm{mL}$ puromycin and $250 \mu \mathrm{g} / \mathrm{mL}$ G418 for 10 days. The sequences of primers were provided in the supplementary Materials and Methods.

\section{MTT assay}

Cell viability was measured using the 3-(4, 5-Dimethyl-2-thiazolyl)-2, 5-diphenyl-2H-tetrazolium bromide (MTT) assay as described previously [57]. $2 \times 10^{3}$ cells were seeded per well in 96-well plates. At each time point, cells were dyed with $100 \mu \mathrm{L} 0.5 \mathrm{mg} / \mathrm{mL}$ MTT for 4 hours at $37^{\circ} \mathrm{C}$, followed by removal of the culture medium and addition of $100 \mu \mathrm{L}$ of dimethyl sulphoxide. The absorbance was measured at $570 \mathrm{~nm}$, with $655 \mathrm{~nm}$ as the reference wavelength.

\section{Anchorage-independent growth ability assay}

Cells were trypsinized and suspended in $2 \mathrm{~mL}$ of complete medium plus $0.3 \%$ agar (Sigma) on 6-well plate $\left(5 \times 10^{3}\right.$ cells per well). The cell mixture was plated on top of a bottom layer with $0.66 \%$ agar completed medium mixture. At 10 days, viable colonies that were larger than $0.1 \mathrm{~mm}$ were counted.

\section{Xenografted tumor model, IHC, and H \& E staining}

Female BALB/c-nu mice (5-6 weeks of age, 18-20 g) were purchased from the Center of Experimental Animal of Guangzhou University of Chinese Medicine, and were housed in barrier facilities on a $12 \mathrm{~h}$ light/dark cycle. All experimental procedures were approved by the Institutional Animal Care and Use Committee of Sun Yatsen University. The mice were randomly divided into two groups ( $n=6$ /group). One group of mice was inoculated subcutaneously with SK-BR-3/pMSCV-vector cells $\left(5 \times 10^{6}\right)$ in the left mammary fat pad and with SKBR-3/E2F8 cells $\left(5 \times 10^{6}\right)$ in the right mammary fat pad per mouse. The other group of mice was inoculated subcutaneously with SK-BR-3/pSUPER-vector cells $\left(5 \times 10^{6}\right)$ in the left mammary fat pad and with SK-BR-3/ E2F8-sh\#1 cells $\left(5 \times 10^{6}\right)$ in the right mammary fat pad per mouse. 7 days later, kinetics of tumor formation was estimated by measuring tumor size at every 3 day interval. Tumor volume was calculated using the equation $\left(\mathrm{L}^{*} \mathrm{~W}^{2}\right) / 2$. On day 34 , tumors were detected by an IVIS imagining system (Caliper), then animals were euthanized, tumors were excised, weighed and paraffin-embedded. Serial $6.0 \mu \mathrm{m}$ sections were cut and subjected to immunohistochemical and H\&E staining. After deparaffinization, sections were IHC analyzed using an anti-Ki67 (Dako, Glostrup, Denmark) or H \& E stained with Mayer's hematoxylin solution. Proliferation index was quantized by counting proportion of Ki67- positive cells among the total number of invasive cells in the area scored based on the recommendations from the International Ki67 in Breast Cancer working group [58].

\section{Luciferase activity assays}

Cells $(3,000)$ were cultured in triplicate in 48-well plates for $24 \mathrm{~h} .100 \mathrm{ng}$ luciferase reporter plasmids or the control-luciferase plasmid, plus $1 \mathrm{ng}$ pRL-TK Renilla plasmid (Promega), were transfected into cells using the Lipofectamine 3000 reagent (Invitrogen), according to the manufacturer's recommendations. Luciferase and Renilla signals were measured $24 \mathrm{~h}$ after transfection, using the Dual Luciferase Reporter Assay Kit (Promega), according to a protocol provided by the manufacturer.

\section{Chromatin immunoprecipitation}

Cells $\left(2 \times 10^{6}\right)$ in a $100 \mathrm{~mm}$ culture dish were treated with $1 \%$ final concentration of formaldehyde to cross-link proteins to DNA, and the reaction was stopped by addition of glycine. The cell lysates were sonicated to shear DNA to sizes of 300-1000 bp. Equal aliquots of chromatin supernatants were incubated with $1 \mu \mathrm{g}$ of antiE2F8, anti-H3K27Ac (Sigma) or anti-immunoglobulin $\mathrm{G}$ antibodies (Millipore, Billerica, MA, USA) overnight at $4{ }^{\circ} \mathrm{C}$ with rotation. After reverse cross-link of protein/ DNA complexes to free DNA, PCR was performed. Specific primers for chromatin immunoprecipitation (ChIP) were presented in the supplementary Materials and Methods.

\section{Statistical analysis}

All statistical analyses were carried out using the SPSS 17.0 statistical software package. The relationship between E2F8 expression and the clinicopathological characteristics was tested by the $\chi^{2}$ test. Bivariate correlations between study variables were calculated by Spearman's rank correlation coefficients. Survival curves were plotted with the Kaplan-Meier method and compared by the log-rank test. Survival data were evaluated using univariate and multivariate Cox-regression analyses. $P<0.05$ in all cases was considered statistically significant.

\section{ACKNOWLEDGMENTS AND FUNDING}

This study was supported by the National Natural Science Foundation of China (Grant No. 81372814 and No.81572687).

\section{CONFLICTS OF INTEREST}

The authors declare that they have no conflicts of interest. 


\section{REFERENCES}

1. Hanahan D, Weinberg RA. Hallmarks of cancer: the next generation. Cell. 2011; 144:646-674.

2. Frolov MV, Dyson NJ. Molecular mechanisms of E2Fdependent activation and pRB-mediated repression. J Cell Sci. 2004; 117:2173-2181.

3. Keyomarsi K, O’Leary N, Molnar G, Lees E, Fingert HJ, Pardee AB. Cyclin E, a potential prognostic marker for breast cancer. Cancer Res. 1994; 54:380-385.

4. Schraml P, Bucher C, Bissig H, Nocito A, Haas P, Wilber K, Seelig S, Kononen J, Mihatsch MJ, Dirnhofer S, Sauter G. Cyclin E overexpression and amplification in human tumours. J Pathol. 2003; 200:375-382.

5. Hedberg Y, Davoodi E, Ljungberg B, Roos G, Landberg G. Cyclin E and p27 protein content in human renal cell carcinoma: clinical outcome and associations with cyclin D. Int J Cancer. 2002; 102:601-607.

6. Cam H, Dynlacht BD. Emerging roles for E2F: beyond the G1/S transition and DNA replication. Cancer cell. 2003; 3:311-316.

7. Muller-Tidow C, Metzger R, Kugler K, Diederichs S, Idos G, Thomas M, Dockhorn-Dworniczak B, Schneider PM, Koeffler HP, Berdel WE, Serve H. Cyclin E is the only cyclin-dependent kinase 2-associated cyclin that predicts metastasis and survival in early stage non-small cell lung cancer. Cancer Res. 2001; 61:647-653.

8. Moelans CB, de Weger RA, Monsuur HN, Vijzelaar R, van Diest PJ. Molecular profiling of invasive breast cancer by multiplex ligation-dependent probe amplification-based copy number analysis of tumor suppressor and oncogenes. Mod Pathol. 2010; 23:1029-1039.

9. Horlings HM, Lai C, Nuyten DS, Halfwerk H, Kristel P, van Beers E, Joosse SA, Klijn C, Nederlof PM, Reinders MJ, Wessels LF, van de Vijver MJ. Integration of DNA copy number alterations and prognostic gene expression signatures in breast cancer patients. Clin Cancer Res. 2010; 16:651-663.

10. Keyomarsi K, Tucker SL, Buchholz TA, Callister M, Ding Y, Hortobagyi GN, Bedrosian I, Knickerbocker C, Toyofuku W, Lowe M, Herliczek TW, Bacus SS. Cyclin E and survival in patients with breast cancer. N Engl J Med. 2002; 347:1566-1575.

11. Scaltriti M, Eichhorn PJ, Cortes J, Prudkin L, Aura C, Jimenez J, Chandarlapaty S, Serra V, Prat A, Ibrahim YH, Guzman M, Gili M, Rodriguez O, et al. Cyclin E amplification/overexpression is a mechanism of trastuzumab resistance in HER2+ breast cancer patients. Proc Natl Acad Sci U S A. 2011; 108:3761-3766.

12. Thomas HD, Wang LZ, Roche C, Bentley J, Cheng Y, Hardcastle IR, Golding BT, Griffin RJ, Curtin NJ, Newell DR. Preclinical in vitro and in vivo evaluation of the potent and specific cyclin-dependent kinase 2 inhibitor NU6102 and a water soluble prodrug NU6301. Eur J Cancer. 2011; 47:2052-2059.
13. Attwooll C, Lazzerini Denchi E, Helin K. The E2F family: specific functions and overlapping interests. EMBO J. 2004; 23:4709-4716.

14. Ziebold U, Lee EY, Bronson RT, Lees JA. E2F3 Loss Has Opposing Effects on Different pRB-Deficient Tumors, Resulting in Suppression of Pituitary Tumors but Metastasis of Medullary Thyroid Carcinomas. Mol Cell Biol. 2003; 23:6542-6552.

15. Lee EY, Cam H, Ziebold U, Rayman JB, Lees JA, Dynlacht BD. E2F4 loss suppresses tumorigenesis in Rb mutant mice. Cancer cell. 2002; 2:463-472.

16. Yamasaki L, Bronson R, Williams BO, Dyson NJ, Harlow E, Jacks T. Loss of E2F-1 reduces tumorigenesis and extends the lifespan of Rb1(+/-)mice. Nat Genet. 1998; 18:360-364.

17. Opavsky R, Tsai SY, Guimond M, Arora A, Opavska J, Becknell B, Kaufmann M, Walton NA, Stephens JA, Fernandez SA, Muthusamy N, Felsher DW, Porcu P, et al. Specific tumor suppressor function for E2F2 in Mycinduced T cell lymphomagenesis. Proc Natl Acad Sci U S A. $2007 ; 104: 15400-15405$.

18. Lee MY, Moreno CS, Saavedra HI. E2F activators signal and maintain centrosome amplification in breast cancer cells. Mol Cell Biol. 2014; 34:2581-2599.

19. Lu Z, Luo RZ, Peng H, Huang M, Nishmoto A, Hunt KK, Helin K, Liao WS, Yu Y. E2F-HDAC complexes negatively regulate the tumor suppressor gene $\mathrm{ARHI}$ in breast cancer. Oncogene. 2006; 25:230-239.

20. Umemura S, Shirane M, Takekoshi S, Kusakabe T, Itoh J, Egashira N, Tokuda Y, Mori K, Osamura YR. Overexpression of E2F-5 correlates with a pathological basal phenotype and a worse clinical outcome. Brit J Cancer. 2009; 100:764-771.

21. Oberley MJ, Inman DR, Farnham PJ. E2F6 negatively regulates BRCA1 in human cancer cells without methylation of histone H3 on lysine 9. J Biol Chem. 2003; 278:42466-42476.

22. Schlereth K, Heyl C, Krampitz AM, Mernberger M, Finkernagel F, Scharfe M, Jarek M, Leich E, Rosenwald A, Stiewe T. Characterization of the p53 cistrome-DNA binding cooperativity dissects p53's tumor suppressor functions. PLoS Genet. 2013; 9:e1003726.

23. Li J, Ran C, Li E, Gordon F, Comstock G, Siddiqui H, Cleghorn W, Chen HZ, Kornacker K, Liu CG, Pandit SK, Khanizadeh M, Weinstein M, et al. Synergistic function of E2F7 and E2F8 is essential for cell survival and embryonic development. Dev Cell. 2008; 14:62-75.

24. Ouseph MM, Li J, Chen HZ, Pecot T, Wenzel P, Thompson JC, Comstock G, Chokshi V, Byrne M, Forde B, Chong JL, Huang K, Machiraju R, et al. A typical E2F repressors and activators coordinate placental development. Dev Cell. 2012; 22:849-862.

25. Weijts BG, Bakker WJ, Cornelissen PW, Liang $\mathrm{KH}$, Schaftenaar FH, Westendorp B, de Wolf CA, Paciejewska M, Scheele CL, Kent L, Leone G, Schulte-Merker S, 
de Bruin A. E2F7 and E2F8 promote angiogenesis through transcriptional activation of VEGFA in cooperation with HIF1. Embo J. 2012; 31:3871-3884.

26. Weijts BG, van Impel A, Schulte-Merker S, de Bruin A. Atypical E2fs control lymphangiogenesis through transcriptional regulation of Ccbe1 and Flt4. PloS one. 2013; 8:e73693.

27. Parisi F, Ariyan S, Narayan D, Bacchiocchi A, Hoyt K, Cheng E, Xu F, Li P, Halaban R, Kluger Y. Detecting copy number status and uncovering subclonal markers in heterogeneous tumor biopsies. BMC genomics. 2011; 12:230.

28. Reimer D, Sadr S, Wiedemair A, Goebel G, Concin N, Hofstetter G, Marth C, Zeimet AG. Expression of the E2F family of transcription factors and its clinical relevance in ovarian cancer. Ann N Y Acad Sci. 2006; 1091:270-281.

29. Deng Q, Wang Q, Zong WY, Zheng DL, Wen YX, Wang KS, Teng XM, Zhang X, Huang J, Han ZG. E2F8 contributes to human hepatocellular carcinoma via regulating cell proliferation. Cancer Res. 2010; 70:782-791.

30. Park SA, Platt J, Lee JW, Lopez-Giraldez F, Herbst RS, Koo JS. E2F8 as a Novel Therapeutic Target for Lung Cancer. J Natl Cancer Inst. 2015; 107.

31. Cancer Genome Atlas N. Comprehensive molecular portraits of human breast tumours. Nature. 2012; 490:61-70.

32. Gyorffy B, Lanczky A, Eklund AC, Denkert C, Budczies J, Li Q, Szallasi Z. An online survival analysis tool to rapidly assess the effect of 22,277 genes on breast cancer prognosis using microarray data of 1,809 patients. Breast Cancer Res Treat. 2010; 123:725-731.

33. Subramanian A, Tamayo P, Mootha VK, Mukherjee S, Ebert BL, Gillette MA, Paulovich A, Pomeroy SL, Golub TR, Lander ES, Mesirov JP. Gene set enrichment analysis: a knowledge-based approach for interpreting genome-wide expression profiles. Proc Natl Acad Sci U S A. 2005; 102:15545-15550.

34. Sandelin A, Wasserman WW, Lenhard B. ConSite: webbased prediction of regulatory elements using cross-species comparison. Nucleic Acids Res 2004; 32:W249-52.

35. Goldhirsch A, Wood WC, Coates AS, Gelber RD, Thurlimann B, Senn HJ, Panel m. Strategies for subtypesdealing with the diversity of breast cancer: highlights of the St. Gallen International Expert Consensus on the Primary Therapy of Early Breast Cancer 2011. Ann Oncol. 2011; 22:1736-1747.

36. Brouckaert $\mathrm{O}$, Laenen A, Vanderhaegen J, Wildiers H, Leunen K, Amant F, Berteloot P, Smeets A, Paridaens R, Christiaens MR, Floris G, Moerman P, Van Limbergen E, et al. Applying the 2011 St Gallen panel of prognostic markers on a large single hospital cohort of consecutively treated primary operable breast cancers. Ann Oncol. 2012; 23:2578-2584.

37. Parker JS, Mullins M, Cheang MC, Leung S, Voduc D, Vickery T, Davies S, Fauron C, He X, Hu Z, Quackenbush JF,
Stijleman IJ, Palazzo J, et al. Supervised risk predictor of breast cancer based on intrinsic subtypes. J Clin Oncol. 2009; 27:1160-1167.

38. Tashiro E, Tsuchiya A, Imoto M. Functions of cyclin D1 as an oncogene and regulation of cyclin D1 expression. Cancer Sci. 2007; 98:629-635.

39. Scime A, Li LL, Ciavarra G, Whyte P. Cyclin D1/cdk4 can interact with E2F4/DP1 and disrupts its DNA-binding capacity. J Cell Physiol. 2008; 214:568-581.

40. Deane NG, Parker MA, Aramandla R, Diehl L, Lee WJ, Washington MK, Nanney LB, Shyr Y, Beauchamp RD. Hepatocellular carcinoma results from chronic cyclin D1 overexpression in transgenic mice. Cancer Res. 2001; 61:5389-5395.

41. Muller H, Bracken AP, Vernell R, Moroni MC, Christians F, Grassilli E, Prosperini E, Vigo E, Oliner JD, Helin K. E2Fs regulate the expression of genes involved in differentiation, development, proliferation, and apoptosis. Genes Dev. 2001; 15:267-285.

42. Ishida S, Huang E, Zuzan H, Spang R, Leone G, West M, Nevins JR. Role for E2F in control of both DNA replication and mitotic functions as revealed from DNA microarray analysis. Mol Cell Biol. 2001; 21:4684-4699.

43. Taylor-Harding B, Aspuria PJ, Agadjanian H, Cheon DJ, Mizuno T, Greenberg D, Allen JR, Spurka L, Funari V, Spiteri E, Wang Q, Orsulic S, Walsh C, et al. Cyclin E1 and RTK/RAS signaling drive CDK inhibitor resistance via activation of E2F and ETS. Oncotarget. 2015; 6:696-714. doi: 10.18632/oncotarget.2673.

44. Burkhart DL, Sage J. Cellular mechanisms of tumour suppression by the retinoblastoma gene. Nat Rev Cancer. 2008; 8:671-682.

45. Asghar U, Witkiewicz AK, Turner NC, Knudsen ES. The history and future of targeting cyclin-dependent kinases in cancer therapy. Nat Rev Drug Discov. 2015; 14:130-146.

46. DeGregori J, Johnson DG. Distinct and Overlapping Roles for E2F Family Members in Transcription, Proliferation and Apoptosis. Curr Mol Med. 2006; 6:739-748.

47. Maiti B, Li J, de Bruin A, Gordon F, Timmers C, Opavsky R, Patil K, Tuttle J, Cleghorn W, Leone G. Cloning and characterization of mouse E2F8, a novel mammalian E2F family member capable of blocking cellular proliferation. $\mathrm{J}$ Biol Chem. 2005; 280:18211-18220.

48. Christensen J, Cloos P, Toftegaard U, Klinkenberg D, Bracken AP, Trinh E, Heeran M, Di Stefano L, Helin K. Characterization of E2F8, a novel E2F-like cell-cycle regulated repressor of E2F-activated transcription. Nucleic Acids Res. 2005; 33:5458-5470.

49. Moon NS, Frolov MV, Kwon EJ, Di Stefano L, Dimova DK, Morris EJ, Taylor-Harding B, White K, Dyson NJ. Drosophila E2F1 has context-specific pro- and antiapoptotic properties during development. Dev Cell. 2005; 9: $463-475$. 
50. Chong JL, Wenzel PL, Saenz-Robles MT, Nair V, Ferrey A, Hagan JP, Gomez YM, Sharma N, Chen HZ, Ouseph M, Wang SH, Trikha P, Culp B, et al. E2f1-3 switch from activators in progenitor cells to repressors in differentiating cells. Nature. 2009; 462:930-934.

51. Lee BK, Bhinge AA, Iyer VR. Wide-ranging functions of E2F4 in transcriptional activation and repression revealed by genome-wide analysis. Nucleic Acids Res. 2011; 39:3558-3573.

52. Zhan L, Huang $\mathrm{C}$, Meng $\mathrm{XM}$, Song $\mathrm{Y}$, Wu XQ, Miu CG, Zhan XS, Li J. Promising roles of mammalian E2Fs in hepatocellular carcinoma. Cell Signal. 2014; 26:1075-1081.

53. Bakker WJ, Weijts BG, Westendorp B, de Bruin A. HIF proteins connect the RB-E2F factors to angiogenesis. Transcription. 2013; 4:62-66.

54. Li J, Zhang N, Song LB, Liao WT, Jiang LL, Gong LY, Wu J, Yuan J, Zhang HZ, Zeng MS, Li M. Astrocyte elevated gene-1 is a novel prognostic marker for breast cancer progression and overall patient survival. Clin Cancer Res. 2008; 14:3319-3326.
55. Zhou CH, Ye LP, Ye SX, Li Y, Zhang XY, Xu XY, Gong LY. Clinical significance of SOX9 in human non-small cell lung cancer progression and overall patient survival. J Exp Clin Cancer Res. 2012; 31:18.

56. Lin C, Song L, Liu A, Gong H, Lin X, Wu J, Li M, Li J. Overexpression of AKIP1 promotes angiogenesis and lymphangiogenesis in human esophageal squamous cell carcinoma. Oncogene. 2015; 34:384-393.

57. Li X, Liang W, Liu J, Lin C, Wu S, Song L, Yuan Z. Transducin (beta)-like $1 \mathrm{X}$-linked receptor 1 promotes proliferation and tumorigenicity in human breast cancer via activation of beta-catenin signaling. Breast Cancer Res. 2014; $16: 465$.

58. Dowsett M, Nielsen TO, A’Hern R, Bartlett J, Coombes RC, Cuzick J, Ellis M, Henry NL, Hugh JC, Lively T, McShane L, Paik S, Penault-Llorca F, et al. Assessment of Ki67 in breast cancer: recommendations from the International Ki67 in Breast Cancer working group. J Natl Cancer Inst. 2011; 103:1656-1664. 